\title{
RECTAL ADVANCEMENT FLAP TREATMENT COMPARED WITH SETON FOR HIGH TRANSSPHINCTERIC PERIANAL FISTULA
}

\author{
Mohammed Khairy Mohammed, Zaki Abdelgawad Allam, Nawel El-Sayed Hussein \& \\ Nabil Abdel Azim Hamrah \\ General Surgery department, Faculty of Medicine, Zagazig University, Egypt.
}

ABSTRACT
Background: Treatment of anal fistula is a balance between maximizing the chances of successful healing and avoiding
complications particularly incontinence from division of the anal sphincters. Many surgical procedures have been used
in the treatment of anal fistula, with varying success. Endorectal advancement flap can be a useful tool for the surgeon
faced with an anal fistula. This study aims to compare outcomes for rectal flap advancement in comparison to seton
placement in treating high transsphincteric perianal fistula.
Subjects \& methods: The study included 54 patients with high transsphincteric perianal fistulas; 27 patients were treated
by rectal partial thickness advancement flap and the other 27 patients were treated by seton placement.
Results: Results proved to be better with rectal advancement flap than seton regarding time to complete healing,
postoperative wound infection, postoperative continence and recurrence.
Conclusion: Rectal Advancement Flap was found to be a promising and a more effective procedure than seton with
better healing rates and less liability for postoperative incontinence or recurrence.
Keywords: High perianal fistula, rectal advancement flap, seton.
Corressponding Author: Mohammed Khairy Mohammed.
E-mail: dr.m khairy@yahoo.com Tel: $\mathbf{0 1 0 0 6 2 1 5 7 8 5}$

\section{INTRODUCTION}

$\mathbf{T}$ he cryptoglandular fistula is by far the most common cause of anoperineal suppuration. The disease entity has long been known and described, but it is the subject of an increasingly abundant literature, especially in the last 20 years, due to the introduction of sphincter sparing techniques. The annual incidence of cryptoglandular fistula varies from $12-28 / 100000$. The sex ratio is $2-3$ men per woman. The average age of onset is between 20 and 50 years [1].

According to the cryptoglandular hypothesis, intersphinteric gland infection is the initiating event in the formation of perianal fistulas. The sepsis arising within these glands can spread into the intersphincteric space, and from here towards the different anorectal planes causing abscesses and fistulae. Parks suggested the mostwidely used classification of intersphincteric, transphincteric, suprasphincteric, and extrasphincteric fistulas [2].

The typical symptom of anal fistula is discharge from a perianal opening. The tract of the fistula and its relationship to the sphincter muscle can be investigated by probing and/or dyeing intraoperatively with the patient under anesthesia. Magnetic resonance imaging (MRI) can be employed either as an external investigation with or without contrast medium. It is to be preferred to endosonography for lesions distant from the anus, so it is better for diagnosis of high perianal fistula and to determine its extent. Other advantages of MRI are that it allows pain-free acquisition of images that can be evaluated independently of the examiner [3].

Conventional classification and treatment depends on the level of the internal opening and the extent of involvement of the external sphincter encompassed by the fistulous track [4].

Low transsphincteric fistulas involve the lower $3^{\text {rd }}$ of the external anal sphincter mechanism and are generally treated by fistulotomy with a high success rate for cure. High transsphincteric fistulas involving the upper two thirds of the external sphincter remain a surgical challenge because incontinence will result from the division of muscle involving more than one third of the sphincter [5].

The ultimate goal of fistula surgery is to eradicate it without disturbing the anal sphincter mechanism. To achieve the objective in high perianal fistula different surgical techniques have been described in literature from time to time [4].

Several treatment strategies have been practiced in order to preserve the sphincter 
mechanism, including draining setons, cutting setons, rectal mucosal or full-thickness advancement flaps, rerouting, two-stage seton fistulotomy, fistulectomy, anal fistula plug, ligation of the intersphincteric fistula tract (LIFT), fistulotomy with reconstruction of the sphincter mechanism, or fibrin glue. The oldest and theoretically the simplest technique is to use a seton, the well-known variations in modern surgical practice being cutting setons, drainage setons, and two- stage seton fistulotomy [6].

Possibly the gold standard for treating complex fistula is endorectal advancement flap surgery, as described by Noble at the beginning of the 20th century, with later modifications. Technically, after surgically removing the extrasphincteric part of the tract, the mucosa is resected distal to the internal orifice of the fistula and a flap is created with a wide base using rectal submucosa or mucosa, partially including the internal anal sphincter or even including its entire thickness. Afterwards, the internal orifice of the fistula is closed and the repair is covered with the flap [7].

\section{PATIENTS \& METHODS}

This randomized clinical trial study was carried out in General Surgery Department, Zagazig University Hospitals from August 2015 to October 2017and included 54 patients with high transsphincteric perianal fistulas. In our study patients with the following criteria were excluded: low perianal fistulas, rectovaginal fistulas, fistulas of inflammatory bowel disease, fistulas due to specific infection (e.g. Tuberculosis) and fistulas due to malignancy.The 54 patients treated for high perianal fistula were devided into 2 groups; group A with 27 patients treated by rectal partial thickness advancement flap and group $\mathrm{B}$ included the other 27 patients were treated by seton placement.

Preoperatively, full history from all the patients was taken that revealed previous fistula surgery (recurrent fistula) in 4 patients in group A and 2 patients in group B. All the patients gave history of perianal suppuration in a certain time. Physical examination to all the patients was done by inspection and digital rectal examination to determine the sites of external and internal openings. MRI to determine the type and the extent of the fistula was done to diagnose the presence of high perianal fistula. Routine preoperative investigations were done for all the patients in the form of: Complete Blood Count -Bleeding profile: PT, PTT and INR - Liver Function Tests - Kidney Function Tests - Random blood sugar.

Surgical technique: mainly spinal anesthesia was used in both groups except in some patients for them general anesthesia was used on their demand.operations were performed either in the prone jack knife position or in the lithotomy position.The internal opening of the fistulous tract was identified by injection of hydrogen peroxide through the external orifice to avoid formation of a false track. After identification of internal opening, probing of the track was done.

In both groups, the standard procedure was to perform core fistulectomy and traversing the external sphincter until the internal sphincter was exposed the track was then transected and the crypt bearing tissue around the internal opening of the fistula is excised. Skin over the distal part of the fistula will be lay open. The next step differs in both groups as follows: (1) Use of rectal advancement flap for group A. The principal steps are: horizontal incision of the rectal mucosa below the primary orifice, upward dissection of a rectal flap whose thickness includes mucosa, submucosa and partial part of internal muscle layer over a length of 40 $50 \mathrm{~mm}$, the base of the advancement flap was kept wide enough ( 2 to 3 times the apex width) with a part of the internal sphincter included in the flap to ensure adequate circulation in the flap, excision of the distal portion of the flap including the mucosal fistular orifice.The transsphincteric fistula opening in the internal sphincter was closed using 3/0 Vicryl sutures (figure, 1). 


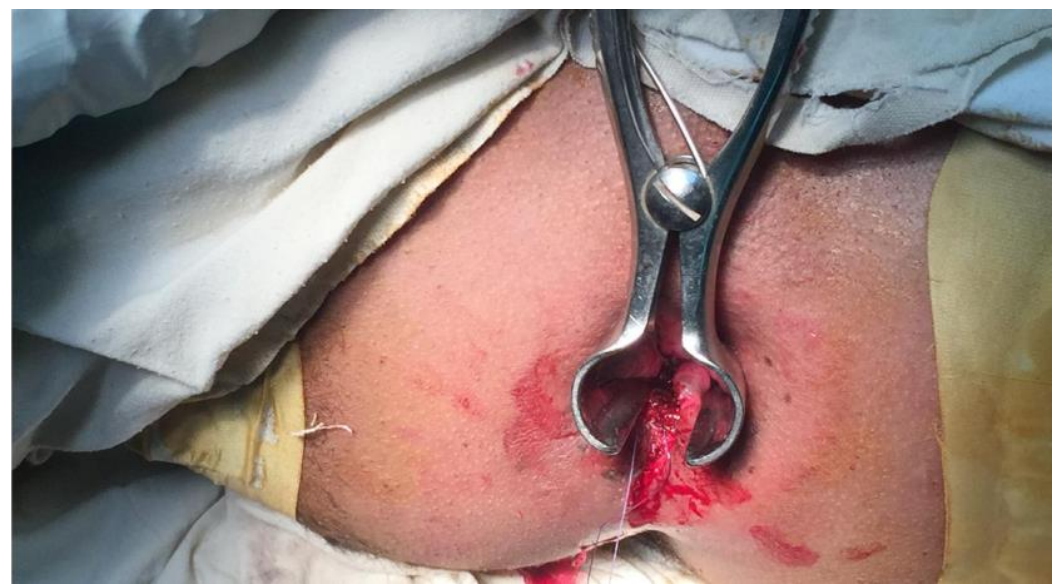

Figure (1): Closure of the transsphincteric fistula opening in the internal sphincter.

Inferior transposition of the flap to cover the primary orifice and then tension-free suture to the lateral and distal mucosal margins of the wound below the level of the primary orifice using absorbable suture material (3/0 Vicryl suture) (figure, 2).

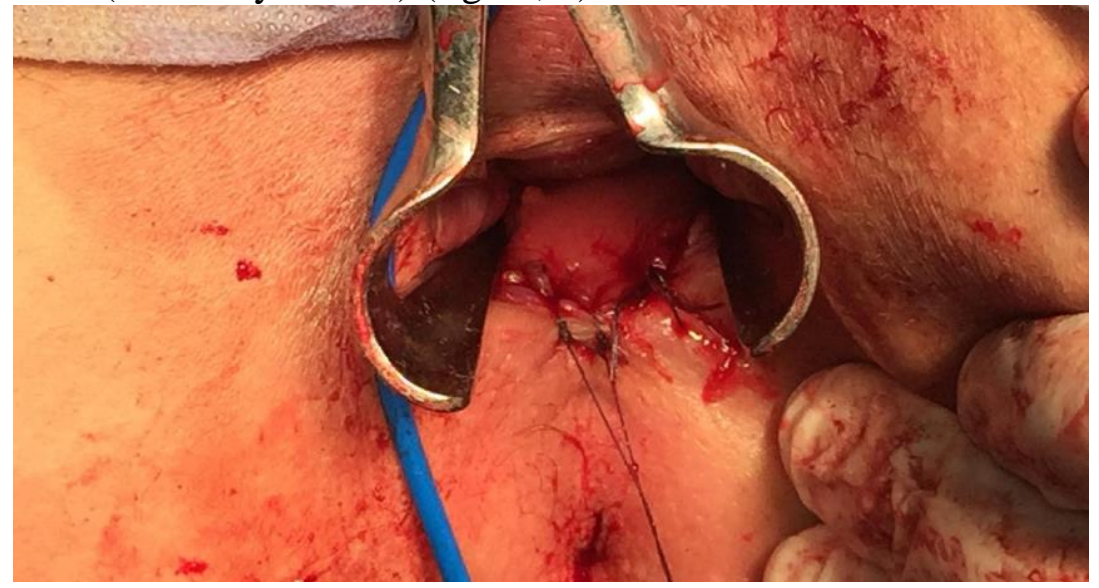

Figure (2): Tension-free suturing of the lateral and distal mucosal margins of the flap.

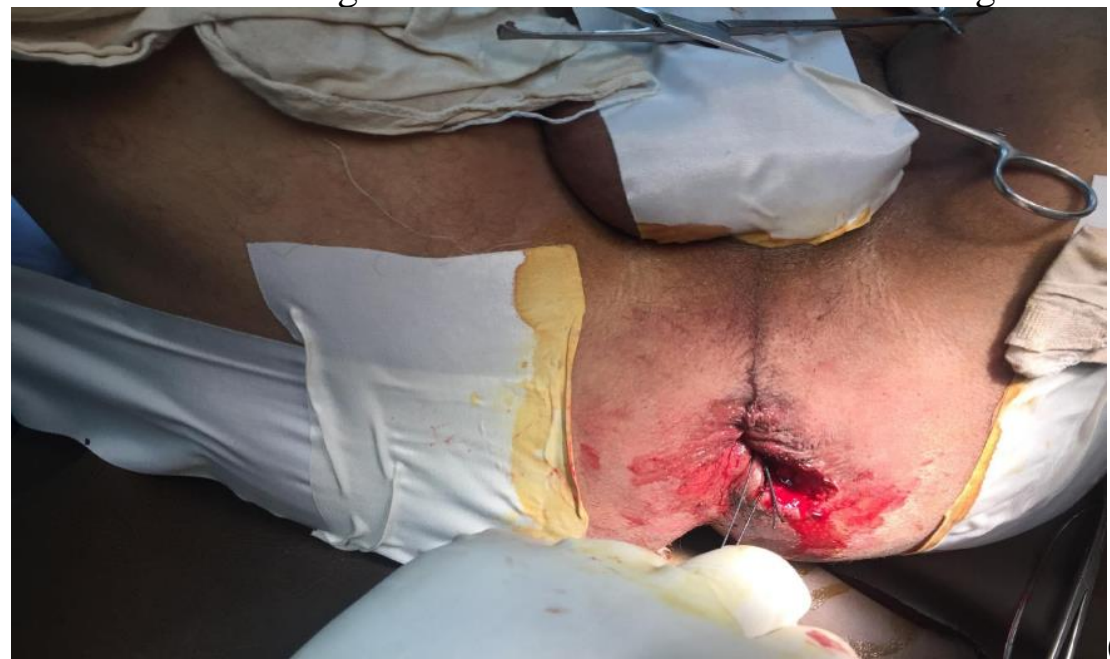

Cutting seton placement for group B. A 0 or 1 silk suture is adopted as the seton material during the operation. The seton is passed through the fistulous tract and knotted in a manner that allow its frequent tightening manually during postoperative follow up visits and tightened by a surgeon to the desired tension (figure, 3). The seton is tightened in the outpatient department manually without anaesthesia maintaining the necessary tension until the seton cut through the muscle. The seton is re-tightened for the first time during the second week after surgery and then at weekly intervals. Curettage is also performed at the same time to remove granulation tissue and overlying skin, to prevent recurrence of a fistulous tract. 
Figure (3): Cutting seton placement

Follow up of our patients was done for about 6 months (in the outpatient clinic, weekly in the first 2 months then every month) with clinical assessment of the patients as regards incidence of any postoperative complications as pain, bleeding, haematoma, infection, ecchymosis, disruption, incidence of any degree of postoperative incontinence and recurrence defined as a discharge or abscess arising in the same area or by obvious evidence of fistulation.

\section{RESULTS}

Data collected throughout history, basic clinical examination, laboratory investigations and outcome measures coded, entered and analyzed using Microsoft Excel software. Data were then imported into Statistical Package for the Social Sciences (SPSS version 20.0) software for analysis. According to the type of data qualitative represent as number and percentage, quantitative continues group represent by mean $\pm \mathrm{SD}$, the following tests were used to test differences for significance; difference and association of qualitative variable by Chi square test $\left(\mathrm{X}^{2}\right)$. Differences between parametric quantitative independent groups by $\mathrm{t}$ test. $\mathrm{P}$ value was set at $<0.05$ for significant results $\&<0.001$ for high significant result.

Fifty four patients contributed to the present prospective study. The mean age in group A was 38 years \pm 10.98 (range from 27 - 65 years) and in group B was 35 years \pm 10.91 (range from $20-65$ years). Twenty one patients of group A and 20 patients of group B were male. Group A $(n=27)$ was managed by rectal advancement flap technique and Group B $(n=27)$ was managed by seton technique.

The operation time, postoperative hospital stay and time to complete healing in both groups are shown in table (1). There was no statistically significant difference between both groups as regards operative time and postoperative hospital stay, however there was statistically significant difference between both groups in favour of group A as regards time to complete healing with the mean period to complete healing of 30 days in group A and 77 days in group B.

Table (1): Operation time, hospital stay and healing time.

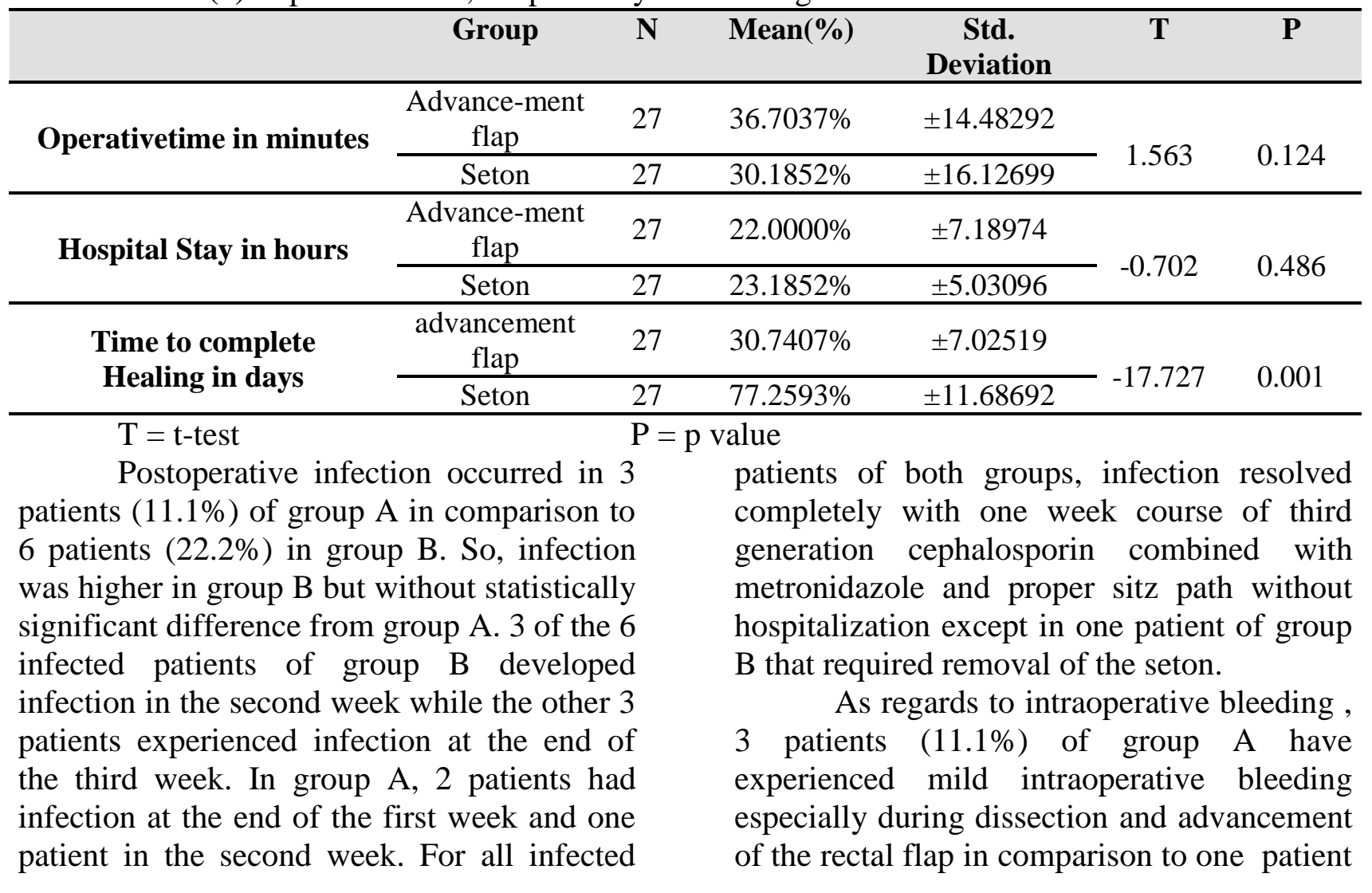


in group B that showed intraoperative bleeding. Although intraoperative bleeding was more in group A, this difference remains statistically insignificant. In all cases intraoperative bleeding could be controlled with regular hemostatic measures using diathermy, compression or packing. Also, it was capable to reduce bleeding in subsequent patients of group A by submucosal injection of diluted adrenaline (1/10000). No cases in group A developed postoperative bleeding. Two patients $(7.4 \%)$ of group B developed postoperative bleeding, one of them in the second postoperative day and the other case at the end of the second week during tightening of the seton and both cases was managed by packing and generally this difference remains statistically insignificant.

Regarding postoperative incontinence, 2 cases $(7.4 \%)$ of group A developed minor incontinence to flatus in comparison to 4 cases $(14.8 \%)$ in group B that developed minor incontinence in the form of soiling or incontinence to flatus. All these cases resolved spontaneously during a period of 2-4 weeks postoperatively. This difference is statistically insignificant.

Three patients $(11.1 \%)$ of group A developed postoperative fistula recurrence. One of them, recurrence was due to infection.
Recurrence occured by the end of the $3^{\text {rd }}$ month in 1 patient and at the $6^{\text {th }}$ month in the other 2 patients. On the other hand, 5 patients (18.5\%) of group B developed postoperative fistula recurrence. In 3 of them, recurrence was due to infection. The incidence of recurrence increased with longer follow up with 1 patient by the end of the $2^{\text {nd }}$ month, another patient by the end of the $4^{\text {th }}$ month and a $3^{\text {rd }}$ patient by the end of the $5^{\text {th }}$ month. At the $6^{\text {th }}$ month, 2 more patients developed recurrence. Recurrence rate was higher in group B than group A but this difference remains not stastistically significant. Three of the recurrent cases of group B were treated by rectal flap advancement. The other 2 recurrent cases were treated by lay open and ligation of interfistulous tract (LIFT). One recurrent case of group A treated by lay open and the other 2 cases did not complete follow up after recurrence.

The postoperative pain was assessed by use of the visual analog scale. There were significantly higher pain scores in the seton group $(1.7 \pm 0.48$ in the group A vs $4.1 \pm 1.1$ in the group $\mathrm{B}, \mathrm{p}=0.002$ ) as shown in table (2). Pain also was more in the group B during the period of sequential tightening of the seton.

Table (2): Postoperative pain assessed visual analog scale

\begin{tabular}{|c|c|c|c|c|c|c|}
\hline & Group & $\mathbf{N}$ & Mean & $\begin{array}{c}\text { Std. } \\
\text { Deviation }\end{array}$ & $\mathbf{T}$ & $\mathbf{P}$ \\
\hline \multirow[t]{2}{*}{ VAS } & $\begin{array}{l}\text { Advance- } \\
\text { ment flap }\end{array}$ & 27 & 1.7037 & \pm 0.48292 & \multirow[t]{2}{*}{-3.447} & \multirow[t]{2}{*}{0.002} \\
\hline & Seton & 27 & 4.1852 & \pm 1.12699 & & \\
\hline
\end{tabular}

The postoperative satisfaction of the patients in both groups was evaluated using a satisfaction score that ranges from 0 for nonsatisfaction to 10 for the highest degree of satisfaction. Satisfaction score was significantly higher in the rectal advancement group group $(8.5 \pm 2.1$ in the group A vs $4.2 \pm 1$. in the group $B, p=0.003$ ) as shown in table (3). 
Table (3): postoperative satisfaction evaluated by satisfaction score

\begin{tabular}{ccccccccc}
\hline & Group & N & Mean & $\begin{array}{c}\text { Std. } \\
\text { Deviation }\end{array}$ & T & P \\
\hline \multirow{2}{*}{ Satisfaction score } & $\begin{array}{c}\text { Advance- } \\
\text { ment flap }\end{array}$ & 27 & 8.5421 & \pm 2.18974 & 3.321 & 0.003 \\
\cline { 2 - 5 } & Seton & 27 & 4.2145 & \pm 1.02166 & \\
\hline T $=$ t-test & \multicolumn{5}{c}{$\mathrm{P}=\mathrm{p}$ value } & &
\end{tabular}

\section{DISCUSSION}

Fistula in ano is a common condition associated with appreciable inconvenience and morbidity to the patient. High transphincteric perianal fistula represents a technical challenge for surgical management [4].

As simple and low anal fistulas can be treated safely only by fistulotomy, the management of high and complex fistulas needs to balance the outcomes of cure and continence. There is a risk of sphincter muscle damage during fistulotomy, and this might lead to an unacceptable risk of anal incontinence of varying degrees. The degree of incontinence depends on the amount of damaged muscle, preexisting sphincter damage, and scarring of the anal canal [6].

Considering the variable results of different surgical methods as reported in several studies, it is believed that an endorectal flap can be considered a selective treatment for high type fistulas, since sphincter damage and recurrence is less than with other surgical methods [8]. The rectal advancement flap achieves healing of the fistula in a significant number of patients, while avoiding any sphincter division and therefore the development of further incontinence [4].

Our study included 54 patients. The mean age in patients treated with rectal advancement flap (group A) was 37.9 years and in patients treated with seton (group B) was 36.1 years. Twenty one (77.8) patients of group A and 20 (74.1) patients of group B were males. Group A was managed by rectal advancement flap and Group B was managed by seton. In comparison with a study performed by Chung et al. in 2009 and included 232 patients who had high transsphincteric fistulas of cryptoglandular origin, the median age was 47 (range 21-82) of them, 86 patients were treated with seton placement and 96 with an advancement flap. Seventy patients $(81.4 \%)$ of the seton group and 71 patients $(73.9 \%)$ of the advancement flap group were males [5].

In our study the mean operation time was 37 minutes. Khafagy et al. found in a study included 40 patients with high transsphincteric perianal fistula treated by partial rectal wall advancement flap (20 patients) or mucosal advancement flap (20 patients) that the adding of circular muscle layer in a rectal advancement flap is associated with better outcome as regard the recurrence rate and continence in treatment of high perianal fistula. The mean operation time in their study for partial rectal wall advancement flap was 37 minutes [4].

Chung et al. in 2009 reported that the healing rate at week 12 was $60 \%$ for flap advancement and $32 \%$ for seton. Healing rates were significantly different between treatment groups. In our Study, there was statistically significant difference between both groups in favour of group A as regards time to complete healing with the mean period to complete healing of 30.7 days in group $\mathrm{A}$ and 77.3 days in group $\mathrm{B}$ [5]. Ghahramani et al. study included 40 patients that were treated by the endorectal flap technique, reported that complete healing was achieved in $28(70 \%)$ patients as confirmed by examination four weeks after surgery [8].

In our study intraoperative bleeding occurred in 3 patients $(11.1 \%)$ of group A and 1 patient $(3.7 \%)$ in group B. Although intraoperative bleeding was more in group A, this difference was statistically insignificant. In all cases intraoperative bleeding could be controlled with regular hemostatic measures using diathermy, compression or packing. 
Also, submucosal injection of adrenaline (1/10000) was found to be a good tool to reduce intraoperative bleeding. Postoperative bleeding occurred in 2 patients $(7.4 \%)$ of group $\mathrm{B}$, one of them in the second postoperative day and the other case at the end of the second week during tightening of the seton and both cases was managed by packing. No cases in group A showed postoperative bleeding and generally this difference remained statistically insignificant. In a study by Mushaya et al. that included 39 patients who were randomized with 25 patients treated by LIFT and 14 patients treated by rectal advancement flap, postoperative bleeding was encountered in 2 (14\%) patients of the rectal advancement flap group [9]. Mogahed et al. in 2015 in a study conducted on 18 patients with high anal fistula who were treated with cutting seton over a 3-year period from Marsh 2011 to July 2014, reported that no $(0 \%)$ postoperative significant bleeding were noted [10].

Regarding postoperative incontinence, 4 cases $(14.8 \%)$ in group B developed minor incontinence in the form of soiling or incontinence to flatus in comparison to 2 cases $(7.4 \%)$ of group A that developed minor incontinence to flatus. All these cases resolved spontaneously during a period of $2-$ 4 weeks postoperatively. This difference is statistically insignificant. Mushaya et al. in a study included 39 patients who were randomized with 25 patients treated by LIFT and 14 patients treated by rectal advancement flap, one patient (7\%) in the rectal advancement flap group had minor incontinence that resolved within a few weeks [9]. In a study by Chuang-Wei et al., 2008 that included 112 patients treated by cutting seton, total continence disorders were noted in 27 patients $(24.1 \%)$, including gas incontinence in 21 patients $(18.6 \%)$ liquid stool incontinence in 6 patients $(5.4 \%)$ and no patient had solid stool incontinence [11].

In our study, 5 patients $(18.5 \%)$ of group B developed postoperative fistula recurrence. In 3 of them, recurrence was due to infection. The incidence of recurrence increased with longer follow up with one patient by the end of the second month, another patient by the end of the fourth month and a third patient by the end of the fifth month. At the sixth month, two more patients developed recurrence. On the other hand, 3 patients $(11.1 \%)$ of group A developed postoperative fistula recurrence. One of them, recurrence was due to infection. Recurrence occured by the end of the 3rd month in 1 patient and at the 6th month in the other 2 patients. Recurrences occurred 6 months after complete healing of the external wound denote that closure of the external skin wound does not always mean complete healing. Recurrence rate was higher in group B than group A but this difference remained stastistically insignificant probably due to small sample size.

In contrast to our study, Ghahramani et al. reported recurrence in 12 cases $(30 \%)$ during the first year after treatment with rectal flap. Six of these cases had one or more previous failed operations for fistula (fistulotomy, seton insertion or endorectal flap) [8]. While Lykke et al. reported a recurrence rate of $12 \%$ in his study which included 34 patients treated with cutting seton [12].

In our present study the postoperative pain was assessed by use of the visual analog scale and was found to be more in the seton group. Pain also was more in this group during the period of sequential tightening of the seton. Madbouly et al. in his study between 2011 and 2013 that included 70 patients who were randomly assigned to either LIFT or MAF (35 in each group) reported that the postoperative pain that was assessed by use of the visual analog scale after 1 and 4 weeks was significantly higher in MAF group after 1 week. However, after 4 weeks, there was no significant difference between the groups [13].

Also in our study the postoperative satisfaction of the patients in both groups was evaluated using a satisfaction score that ranges from 0 for nonsatisfaction to 10 for the highest degree of satisfaction. Satisfaction score was significantly higher in the rectal advancement flap group, this was due to less postoperative pain in rectal advancement flap group and rapid healing time in comparison to seton group. A more important point is that patients treated with seton had to make 
continuous follow up and frequent tightening of the seton and that contributed to more suffering of the patients. On the other hand, Mushaya et al. in his study that compared between LIFT and rectal advancement flap found that satisfaction scores were higher in the LIFT group relative to the rectal advancement flap group [9].

\section{CONCLUSION}

Surgical treatment of high perianal fistula is challenging. Both seton and rectal advancement flap are widely used sphincter preserving surgical procedures for management of high perianal fistula. Rectal Advancement Flap was found to be a promising and a more effective procedure with better healing rates and less liability for postoperative incontinence or recurrence.

\section{REFERENCES}

1) de Parades V, Zeitoun JD and Atienza P: Cryptoglandular Anal Fistula. Journal of visceral surgery 2010; 147:e203-e215.

2) Sileri P, Cadeddu1 F, D'Ugo S, Franceschilli L, Calabrese E, Fiaschetti Vet al.: Surgery for fistula-in-ano in a specialist colorectal unit: a critical appraisal. BMC Gastroenterology 2011; 11:120.

3) Ommer A, Herold A, Berg E , Farke S, Fürst A, Hetzer $\mathbf{F}$ et al.: Clinical practice guideline: Cryptoglandular anal fistula. Dtsch Arztebl Int. 2011; 108(42): 707-13.

4) Khafagy W, Omar W, El Nakeeb A Fouda E, Yousef $M$ and Farid $M$ : Treatment of anal fistulas by partial rectal wall advancement flap or mucosal advancement flap: A prospective randomized study. International journal of surgery 2010; 8:321-325.
5) Chung W, Kazemi P, Ko D, Sun C, Brown CJ, Raval $M$ and Phang T: Anal fistula plug and fibrin glue versus conventional treatment in repair of complex anal fistulas. The American Journal of Surgery 2009; 197: 604-608.

6) Ege B. Leventog S. Mentes B, Yılmaz $U$ and Öner AY: Hybrid seton for the treatment of high anal fistulas: results of 128 consecutive patients. Tech coloproctol 2014; 18:187-193.

7) Roig $\mathbf{J}$ and Armengol $\mathbf{J}$ : Treatment of Complex Cryptoglandular Anal Fistulas. Does it Still Require an Experienced Surgeon? Cir esp 2013; 91:78-89.

8) Ghahramani L, Mohammad Bananzadeh A, Izadpanah A, Hosseini SV: Late Results of Endorectal Flap in Management of High Type Perianal Fistula. Middle East J Dig Dis 2012; 4: 163-167.

9) Mushaya C, Bartlett L, Schulze B, Yik-Hong Ho: Ligation of intersphincteric fistula tract compared with advancement flap for complex anorectal fistulas requiring initial seton drainage. The American Journal of Surgery 2012; 204 (3):283-289

10) Mogahed M, Elwakeel B and Boraii S: Cutting seton as surgical management of high anal fistula. Al-Azhar Assiut Medical Journal. 2015; 13(2): 10-14.

11) Chuang-Wei $\mathbf{C}$, Chang-Chieh W, Cheng-Wen $\mathrm{H}$, Tsai-Yu L, Chun-Che F and Shu-Wen J: Cutting seton for complex perianal fistula Surgeon 2008; 6 (3): 185-188

12) Lykke A, Steendahl J, Wille-Jørgensen PA: Treating high anal fistulae with slow cutting seton. Ugeskr Laeger. 2010; 172: 516-519.

13) Madbouly KM, El Shazly W, Abbas KS and Hussein AM: Ligation of Intersphincteric Fistula Tract Versus Mucosal Advancement Flap in Patients With High Transsphincteric Fistula-inAno: A Prospective Randomized Trial. Diseases of the Colon \& Rectum 2014; (57)10: 1203-1208 